\title{
Penerapan Metode Backpropagation Dalam Memprediksi Jumlah Penjualan Oli Shell
}

\author{
Chairul Fadlan', Irfan Sudahri Damanik ${ }^{2}$, Jaya Tata Hardinata ${ }^{3}$ \\ Program Studi Sistem Informasi, STIKOM Tunas Bangsa Pematangsiantar \\ Jln. Jenderal Sudirman Blok A No. 1,2,3 Pematangsiantar \\ chairulfadlan116@gmail.com,irfansudahri@gmail.com, jayatatahardinata@gmail.com
}

\begin{abstract}
The application of a prediction is very important to do in research, so that research becomes faster and directed. Just as in predicting the number of shell oil sales, studies and the use of appropriate methods are needed to obtain optimal results. The data used in this study is sales data from PT. Mitra Petra Sejahtera Kota Medan from 2012 to 2017. The algorithm used to make this prediction is the backpropagation algorithm. This algorithm is used to predict future results based on previous data. There are 6 architectural models used in the backpropagation algorithm, among others, 4-2-1 which will later produce predictions with 83\% accuracy, 4-3-1 = 78\%, 4-4-1 = 83\%, 4- 5-1 = 78\%, 4-8-1 = 100\% and 4$10-1=72 \%$. The best architecture of these 6 models is 4-8-1 with an accuracy rate of 94\% with a level of Error 0.001, MSE $=0.04133616$. so this architectural model is good enough to be used to predict the amount of shell oil sales.
\end{abstract}

Keywords: JST, Prediction, Sales, Backpropagation

Abstrak - Penerapan pada sebuah prediksi sangat penting dilakukan dalam penelitian, agar penelitian menjadi lebih cepat dan terarah. Seperti halnya dalam memprediksi jumlah penjuala oli shell, diperlukan adanya kajian-kajian dan penggunaan motode yang tepat untuk mendapatkan hasil yang optimal. Data yang digunakan dalam penelitian ini adalah data penjualan dari PT. Mitra Petra Sejahtera Kota Medan dari tahun 2012 sampai tahun 2017. Algoritma yang digunakan untuk melakukan prediksi ini adalah algoritma backpropagation. Algoritma ini digunakan untuk memprediksi hasil yang akan datang berdasarkan data sebelumnya. Ada 6 model arsitektur yang digunakan pada algoritma backpropagation ini, antara lain, 4-2-1 yang nantinya akan menghasilkan prediksi dengan tingkat akurasi $83 \%, 4-3-1=78 \%, 4-4-1=83 \%, 4-5-1=78 \%, 4-8-1=100 \%$ dan 4-10-1=72\%. Arsitektur tebaik dari ke 6 model ini adalah 4-8-1 dengan tingkat akurasi 94\% dengan tingkat Error 0.001, MSE=0.04133616. sehingga model arsitektur ini cukup baik digunakan untuk memprediksi jumlah penjualan oli shell.

Kata kunci: JST, Prediksi, Penjualan, Backpropagation.

\section{PENDAHULUAN}

Kendaraan sebagai alat transportasi menjadi kebutuhan yang sangat penting, terutama untuk mendukung dan memenuhi kegiatan dan mobilitas seseorang dalam menempuh jarak tertentu, sehingga kendaraan menjadi sebuah kebutuhan bagi masyarakat dalam mencapai tujuan. Seiring dengan semakin banyaknya kendaraan yang diproduksi diindonesia, membuat beberapa perusahaan berlomba-lomba memproduksi kebutuhan kendaraan, salah satunya adalah minyak pelumas mesin/oli. Oli merupakan minyak yang berfungsi sebagai bahan pelumas agar mesin berjalan lancar, mulus dan bebas gangguan. Oli juga berfungsi sebagai pendingin, peredam getaran, bahkan penggunaan oli yang tepat pada mesin dapat berfungsi sebagai penghemat pada konsumsi bahan bakar [1]. Oli 
menjadi kebutuhan kendaraan yang paling dicari oleh masyarakat agar kondisi mesin kendaraan selalu terjaga.

Namun seiring dengan ketidak pastian jumlah stok barang yang laku terjual sering kali menjadi masalah suatu perusahaan dalam memperkirakan jumlah penjualan di masa yang akan datang, apakah akan mengalami kenaikan atau bahkan mengalami penurunan penjualan. Permasalahan tersebut ada ketika sebuah perusahaan ingin mengetahui apakah perlu menambah upaya dalam mempromosikan barang yang akan dijual. Dengan tidak adanya kepastian besarnya jumlah barang yang laku terjual, maka perusahaan tidak mengetahui berapa besar biaya yang kira-kira harus dikeluarkan untuk membayar biaya promosi. Bedasarkan permasalahan tersebut, dibutuhkan sebuah pemodelan arsitektur untuk melakukan prediksi penjualan barang, sehingga perusahaan dapat mengetahui berapa jumlah stok yang harus disediakan pada masa yang akan datang. Pemodelan yang sesuai untuk digunakan sebagai prediksi adalah metode backpropagation. Backpropagation merupakan salah satu algoritma Jaringan Saraf Tiruan yang sering digunakan untuk menyelesaikan masalah-masalah yang rumit dan berkaitan dengan identifikasi input, prediksi, pengenalan pola, dan sebagainya [2]. Berbagai penelitian yang telah dilakukan dengan menggunakan metode backpropagation diantaranya: prediksi jumlah reservasi kamar hotel dengan menggunakan pola 3-6-1 dengan hasil akurasi pengujian sebesar 99.97\% dengan tingkat MSE 0.0009995 dengan tingkat kesalahan 0.03\% [3], analisis prediksi index harga konsumen berdasarkan kelompok kesehatan dengan menggunakanan metode backpropagation dengan menggunakan model arsitektur 12-70-1 yang menghasilkan tingkat akurasi sebesar 92\%, MSE 0.03659742 dengan tingkat error yang digunakan 0.001-0.05 [4].

\section{METODOLOGI PENELITIAN}

\subsection{Penerapan}

Penerapan bukan sekedar aktivitas, tetapi suatu kegiatan yang terencana dan dilakukan secara sungguh-sungguh berdasarkan acuan norma tertentu untuk mencapai tujuan kegiatan [5].

\subsection{Kecerdasan Buatan}

Kecerdasan buatan (artificial Intelligence) merupakan alah satu bagian dari ilmu komputer yang mempelajari bagaimana membuat mesin komputer dapat melakukan pekerjaan seperti dan sebaik yang dilakukan oleh manusia bahkan bisa lebih baik dari pada yang dilakukan manusia [6].

\subsection{Jaringan Saraf Tiruan Backpropagation}

Jaringan saraf tiruan adalah sistem komputasi dimana arsitektur dan operasi di ilhami dari pengetahuan tentang sel saraf biologis di dalam otak, yang merupakan salah satu representasi buatan dari otak manusia yang selalu mencoba menstimulasi proses pembelajaran pada otak manusia tersebut [7]. Istilah buatan digunakan karena jaringan saraf tiruan ini diimplementasikan dengan menggunakan program komputer yang mampu menyelesaikan sejumlah proses perhitungan selama proses pembelajaran [8]. Algoritma backpropagation adalah 
algoritma yang melatih jaringan untuk mendapatkan keseimbangan antara kemampuan jaringan untuk mengenali pola yang digunakan selama pelatihan serta kemampuan jaringan untuk memberikan respon yang benar terhadap pola masukan yang serupa (tetapi tidak sama) dengan pola yang dipakai selama pelatihan [9].

\subsection{Prediksi}

Prediksi atau peramalan merupakan usaha memperkirakan sesuatu yang akan terjadi di waktu mendatang dengan memanfaatkan berbagai informasi yang relavan pada waktu-waktu sebelumnya memalui suatu metode ilmiah [10].

\subsection{Penjualan}

Penjualan adalah suatu kegiatan transaksi yang dilakukan oleh 2 (dua) orang atau lebih dengan memakai alat pembayaran yang sah. Penjualan juga merupakan salah satu sumber dari pendapatan seseorang atau perusahaan yang melangsungkan transaksi jual beli [11].

\subsection{Arsitektur Jaringan}

Arsitektur jaringan yang dipakai untuk melakukan prediksi jumlah penjualan oli shell dapat dilihat pada gambar 1.

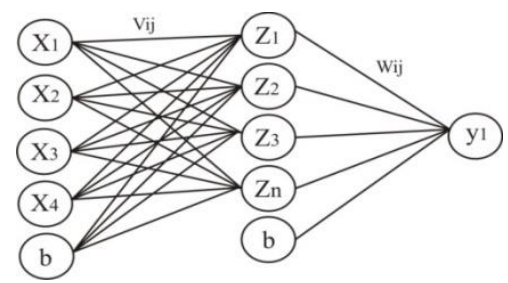

Gambar 1. Arsitektur Jaringan Prediksi Penjualan

Keterangan :

$\mathrm{X}_{1}-\mathrm{X}_{4}$ : Data masukan (input layer)

b : Bias

$\mathrm{V}_{\mathrm{ij}} \quad$ : Bobot ke simpul hidden

$\mathrm{W}_{\mathrm{ij}} \quad$ : Bobot ke simpul output

$\mathrm{Z}_{1}-\mathrm{Z}_{\mathrm{n}}$ : Hidden layer

Y : Hasil keluaran (output)

Pola arsitektur yang digunakan untuk melakukan prediksi jumlah penjualan oli shell yaitu 4-n-1. Dimana 4 adalah node data input, sedangkan jumlah hidden node $\mathrm{n}$ menggunakan aturan 'rule of thumb', serta 1 keluaran.

\subsection{Data Yang Digunakan}

Data yang digunakan dalam penelitian ini adalah data penjualan oli shell yang diperoleh dari PT. Mitra Petra Sejahtera yang beralamat di jalan pemuda baru II no.1-3 Medan mulai tahun 2012-2017. Data ini nantinya akan dibagi menjadi 2 bagian, yaitu data training dan data testing. Data training yang digunakan yakni data tahun 2012-2015 dengan target tahun 2016, sedangkan untuk data testing 
yang digunakan yakni tahun 2013-2016 dengan target 2017. Tabel data dapat dilihat pada tabel 1 .

Tabel 1. Tabel Jumlah Penjualan

\begin{tabular}{|c|c|c|c|c|c|c|c|}
\hline \multirow[t]{2}{*}{ No } & \multirow[t]{2}{*}{ Produk } & \multicolumn{6}{|c|}{ Tahun } \\
\hline & & $\begin{array}{c}2012 \\
\text { (liter) }\end{array}$ & $\begin{array}{c}2013 \\
\text { (liter) }\end{array}$ & $\begin{array}{c}2014 \\
\text { (liter) }\end{array}$ & $\begin{array}{c}2015 \\
\text { (liter) }\end{array}$ & $\begin{array}{c}2016 \\
\text { (liter) }\end{array}$ & $\begin{array}{r}2017 \\
\text { (liter) }\end{array}$ \\
\hline 1 & Advance AX3 & 51543 & 61587 & 28184 & 18992 & 28047 & 21419 \\
\hline 2 & Advance AX5 & 63994 & 77300 & 58568 & 45792 & 64966 & 31931 \\
\hline 3 & Advance AX7 & 28095 & 29180 & 35845 & 29123 & 56887 & 29508 \\
\hline 4 & Advance AX7 Matic & 3621 & 3639 & 5658 & 5246 & 9177 & 3731 \\
\hline 5 & Advance Sx2 & 43524 & 47369 & 23030 & 7841 & 11449 & 3815 \\
\hline 6 & Advance Ultra 4T & 394 & 246 & 211 & 264 & 425 & 169 \\
\hline 7 & Helix HX3 & 47943 & 46504 & 54800 & 49094 & 72593 & 31886 \\
\hline 8 & Helix HX5 & 108485 & 108408 & 102722 & 87097 & 145889 & 50160 \\
\hline 9 & Helix HX7 & 42483 & 42288 & 41979 & 35645 & 71980 & 35716 \\
\hline 10 & Helix HX8 & 2830 & 2874 & 3306 & 2752 & 5220 & 3473 \\
\hline 11 & Helix Ultra & 2294 & 2449 & 2597 & 681 & 1162 & 533 \\
\hline 12 & Rimula R2 40 & 12394 & 12477 & 12287 & 11907 & 30134 & 19583 \\
\hline 13 & Rimula R2 Extra & 2023 & 2205 & 775 & 1670 & 2685 & 4050 \\
\hline 14 & Rimula R3 X & 16124 & 16041 & 70 & 30 & 45 & 35 \\
\hline 15 & Rimula R4 X & 839 & 796 & 28098 & 18023 & 20140 & 8412 \\
\hline 16 & Spirax S2G & 842 & 656 & 1040 & 1328 & 1264 & 588 \\
\hline 17 & Spirax S3 ATF & 423 & 468 & 301 & 708 & 443 & 629 \\
\hline 18 & Spirax S3 G & 402 & 404 & 388 & 361 & 1197 & 505 \\
\hline
\end{tabular}

(Sumber : PT.Mitra Petra Sejahtera)

\subsection{Normalisasi Data}

Data awal yang telah dikumpulkan harus terlebih dahulu dinormalisasi dengan menggunakan fungsi sigmoid. Artinya data yang dinormalisasi nantinya akan menghasilkan nilai antara 0 dan 1 (tidak boleh 0 dan 1), maka transformasi data dilakukan pada interval yang lebih kecil yaitu [0.1; 0.9], ditunjukkan dengan persamaan (1).

$x^{\prime}=\frac{0.8(x-a)}{b-a}+0.1$

Keterangan :

$X^{\prime}=$ Normalisasi data

$x=$ Data yang akan dinirmalisasi

$a=$ Data terendah

$b=$ Data tertinggi

Pada tabel 2 dapat dilihat hasil normalisasi data training. Data ini telah dinormalisasikan menggunakan fungsi sigmoid (persamaan 1) berdasarkan pada tabel 1, yakni tahun 2012-2015 dengan target tahun 201

Tabel 2. Normalisasi Data Training tahun 2012-2015/Target tahun 2016

\begin{tabular}{|c|l|c|c|c|c|c|}
\hline \multirow{2}{*}{ No } & \multirow{2}{*}{ Produk } & \multicolumn{4}{|c|}{ Input } & \multirow{2}{*}{ Target } \\
\cline { 3 - 6 } & & $\mathbf{2 0 1 2}$ & $\mathbf{2 0 1 3}$ & $\mathbf{2 0 1 4}$ & $\mathbf{2 0 1 5}$ & \\
\hline 1 & Advance AX3 & 0.3825 & 0.4376 & 0.2544 & 0.2040 & 0.2537 \\
\hline 2 & Advance AX5 & 0.4508 & 0.5238 & 0.4211 & 0.3510 & 0.4562 \\
\hline
\end{tabular}

Metode backpropagation dalam memprediksi jumlah penjualan oli shell (Chairul Fadlan)|399 


\begin{tabular}{|c|c|c|c|c|c|c|}
\hline \multirow[t]{2}{*}{ No } & \multirow[t]{2}{*}{ Produk } & \multicolumn{4}{|c|}{ Input } & \multirow[t]{2}{*}{ Target } \\
\hline & & 2012 & 2013 & 2014 & 2015 & \\
\hline 3 & Advance AX7 & 0.2539 & 0.2599 & 0.2964 & 0.2596 & 0.4118 \\
\hline 4 & Advance AX7 Matic & 0.1197 & 0.1198 & 0.1309 & 0.1286 & 0.1502 \\
\hline 5 & Advance Sx2 & 0.3386 & 0.3596 & 0.2261 & 0.1428 & 0.1626 \\
\hline 6 & Advance Ultra 4T & 0.1020 & 0.1012 & 0.1010 & 0.1013 & 0.1022 \\
\hline 7 & Helix HX3 & 0.3628 & 0.3549 & 0.4004 & 0.3691 & 0.4980 \\
\hline 8 & Helix HX5 & 0.6948 & 0.6944 & 0.6632 & 0.5775 & 0.9000 \\
\hline 9 & Helix HX7 & 0.3328 & 0.3318 & 0.3301 & 0.2953 & 0.4946 \\
\hline 10 & Helix HX8 & 0.1154 & 0.1156 & 0.1180 & 0.1149 & 0.1285 \\
\hline 11 & Helix Ultra & 0.1124 & 0.1133 & 0.1141 & 0.1036 & 0.1062 \\
\hline 12 & Rimula R2 40 & 0.1678 & 0.1683 & 0.1672 & 0.1651 & 0.2651 \\
\hline 13 & Rimula R2 Extra & 0.1109 & 0.1119 & 0.1041 & 0.1090 & 0.1146 \\
\hline 14 & Rimula R3 X & 0.1883 & 0.1878 & 0.1002 & 0.1000 & 0.1001 \\
\hline 15 & Rimula R4 X & 0.1044 & 0.1042 & 0.2539 & 0.1987 & 0.2103 \\
\hline 16 & Spirax S2G & 0.1045 & 0.1034 & 0.1055 & 0.1071 & 0.1068 \\
\hline 17 & Spirax S3 ATF & 0.1022 & 0.1024 & 0.1015 & 0.1037 & 0.1023 \\
\hline 18 & Spirax S3 G & 0.1020 & 0.1021 & 0.1020 & 0.1018 & 0.1064 \\
\hline
\end{tabular}

Pada tabel 3 dapat dilihat hasil normalisasi data testing. Data ini telah dinormalisasikan menggunakan fungsi sigmoid (persamaan 1) berdasarkan pada tabel 1, yakni tahun 2013-2016 dengan target tahun 2017.

Tabel 3. Normalisasi Data Testing tahun 2013-2016/Target tahun 2017

\begin{tabular}{|c|l|c|c|c|c|c|}
\hline \multirow{2}{*}{ No } & \multirow{2}{*}{ Produk } & \multicolumn{4}{|c|}{ Input } & Target \\
\cline { 3 - 6 } & & $\mathbf{2 0 1 3}$ & $\mathbf{2 0 1 4}$ & $\mathbf{2 0 1 5}$ & $\mathbf{2 0 1 6}$ & \\
\hline 1 & Advance AX3 & 0.4376 & 0.2544 & 0.2040 & 0.2537 & 0.2173 \\
\hline 2 & Advance AX5 & 0.5238 & 0.4211 & 0.3510 & 0.4562 & 0.2750 \\
\hline 3 & Advance AX7 & 0.2599 & 0.2964 & 0.2596 & 0.4118 & 0.2617 \\
\hline 4 & Advance AX7 Matic & 0.1198 & 0.1309 & 0.1286 & 0.1502 & 0.1203 \\
\hline 5 & Advance Sx2 & 0.3596 & 0.2261 & 0.1428 & 0.1626 & 0.1208 \\
\hline 6 & Advance Ultra 4T & 0.1012 & 0.1010 & 0.1013 & 0.1022 & 0.1008 \\
\hline 7 & Helix HX3 & 0.3549 & 0.4004 & 0.3691 & 0.4980 & 0.2747 \\
\hline 8 & Helix HX5 & 0.6944 & 0.6632 & 0.5775 & 0.9000 & 0.4548 \\
\hline 9 & Helix HX7 & 0.3318 & 0.3301 & 0.2953 & 0.4946 & 0.2957 \\
\hline 10 & Helix HX8 & 0.1156 & 0.1180 & 0.1149 & 0.1285 & 0.1189 \\
\hline 11 & Helix Ultra & 0.1133 & 0.1141 & 0.1036 & 0.1062 & 0.1028 \\
\hline 12 & Rimula R2 40 & 0.1683 & 0.1672 & 0.1651 & 0.2651 & 0.1597 \\
\hline 13 & Rimula R2 Extra & 0.1119 & 0.1041 & 0.1090 & 0.1146 & 0.1220 \\
\hline 14 & Rimula R3 X & 0.1878 & 0.1002 & 0.1000 & 0.1001 & 0.1000 \\
\hline 15 & Rimula R4 X & 0.1042 & 0.2539 & 0.1987 & 0.2103 & 0.1460 \\
\hline 16 & Spirax S2G & 0.1034 & 0.1055 & 0.1071 & 0.1068 & 0.1031 \\
\hline 17 & Spirax S3 ATF & 0.1024 & 0.1015 & 0.1037 & 0.1023 & 0.1033 \\
\hline 18 & Spirax S3 G & 0.1021 & 0.1020 & 0.1018 & 0.1064 & 0.1026 \\
\hline
\end{tabular}

\section{HASIL DAN PEMBAHASAN}

\subsection{Analisis}

Sebelum training dilakukan, terlebih dahulu menentukan nilai parameter yang diinginkan untuk memperoleh hasil yang optimal. Parameter yang digunakan secara umum pada aplikasi Matlab untuk training dan testing dapat dilihat pada kode berikut : 
$>>$ net=newff(minmax (P),[Hidden,Target], \{'logsig','purelin'\},'traingdx');

$>$ net.IW $\{1,1\}$;

$>$ net.b $\{1\}$;

$>$ net.LW $\{2,1\}$;

$>$ net.trainparam.epochs $=10000$;

$>$ net. Trainparam.goal $=0.001$;

$>$ net.trainparam.lr=0.01;

\subsection{Hasil}

Penelitian ini menggunakan 6 arsitektur. Antara lain 4-2-1, 4-3-1, 4-4-1, 4-51, 4-8-1, dam 4-10-1. Dari ke 6 arsitektur tersebut, arsitektur terbaik ialah 4-8-1 dengan tingkat akirasi sebesar 94\% serta epoch sebesar 1419 iterasi.

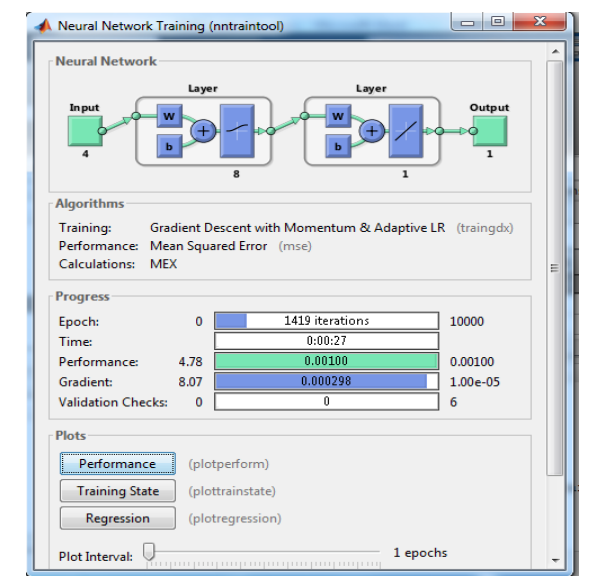

Gambar 2. Data Training Dengan Model Arsitektur 4-8-1

Dari gambar 2 data training dengan model arsitektur 4-8-1 dapat dijelaskan bahwa epoch yang terjadi sebesar 1419 iterasi dengan lama waktu 27 detik.

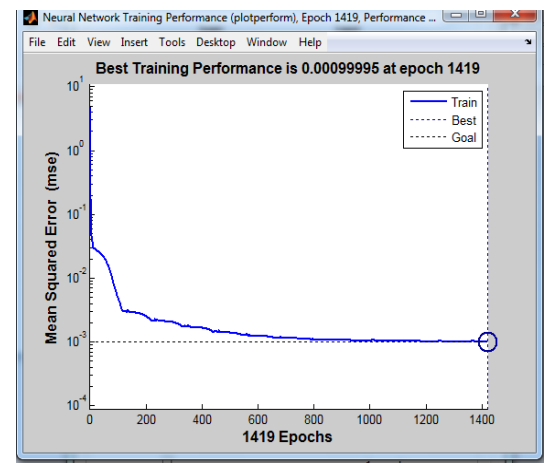

Gambar 3. Best Training Performance Dengan Arsitektur 4-8-1

Berdasarkan gambar 3 dapat dijelaskan bahwa performance pelatihan terbaik adalah 0.00099995 pada epoch 1419 . Tabel 4 merupakan hasil akurasi dari model arsitektur terbaik dengan algoritma backpropagation, yakni 4-8-1. Tabel 4 ini dibuat dan dihitung dengan menggunakan Microsoft Excel. 
Tabel 4. Arsitektur Terbaik Algoritma Backpropagation Dengan Model 4-8-1

\begin{tabular}{|c|c|c|c|c|c|c|c|c|c|}
\hline \multirow[t]{2}{*}{ No } & \multicolumn{4}{|c|}{ Data Training } & \multicolumn{4}{|c|}{ Data Testing } & \multirow[t]{2}{*}{ Hasil } \\
\hline & Target & Output & Error & SSE & Target & Output & error & $S S E$ & \\
\hline 1 & 0.2537 & 0.2395764 & 0.01409 & 0.00019852 & 0.2173 & 0.4396232 & -0.22231 & 0.04942171 & 1 \\
\hline 2 & 0.4562 & 0.4569779 & -0.00082 & 0.00000067 & 0.2750 & 0.340329 & -0.06536 & 0.00427194 & 1 \\
\hline 3 & 0.4118 & 0.4218301 & -0.00998 & 0.00009968 & 0.2617 & 0.5005702 & -0.23889 & 0.05706882 & 1 \\
\hline 4 & 0.1502 & 0.1329447 & 0.01722 & 0.00029668 & 0.1203 & 0.1349158 & -0.01462 & 0.00021365 & 1 \\
\hline 5 & 0.1626 & 0.1788619 & -0.01623 & 0.00026346 & 0.1208 & 0.1651374 & -0.04438 & 0.00196937 & 1 \\
\hline 6 & 0.1022 & 0.1278007 & -0.02563 & 0.00065711 & 0.1008 & 0.1279405 & -0.02718 & 0.00073865 & 1 \\
\hline 7 & 0.4980 & 0.5014593 & -0.00347 & 0.00001204 & 0.2747 & 0.4597896 & -0.18507 & 0.03424995 & 1 \\
\hline 8 & 0.9000 & 0.8998616 & 0.00014 & 0.00000002 & 0.4548 & 1.2016172 & -0.74678 & 0.55767421 & 1 \\
\hline 9 & 0.4946 & 0.4974365 & -0.00281 & 0.00000789 & 0.2957 & 0.4800587 & -0.18433 & 0.03397754 & 1 \\
\hline 10 & 0.1285 & 0.12988 & -0.00141 & 0.00000200 & 0.1189 & 0.1308882 & -0.01200 & 0.00014410 & 1 \\
\hline 11 & 0.1062 & 0.1283976 & -0.02219 & 0.00049235 & 0.1028 & 0.1274126 & -0.02465 & 0.00060781 & 1 \\
\hline 12 & 0.2651 & 0.1495679 & 0.11555 & 0.01335065 & 0.1597 & 0.1915532 & -0.03188 & 0.00101663 & 1 \\
\hline 13 & 0.1146 & 0.1279634 & -0.01340 & 0.00017960 & 0.1220 & 0.1294912 & -0.00744 & 0.00005539 & 1 \\
\hline 14 & 0.1001 & 0.1094758 & -0.00939 & 0.00008824 & 0.1000 & 0.0898701 & 0.01012 & 0.00010261 & 0 \\
\hline 15 & 0.2103 & 0.1829045 & 0.02739 & 0.00075042 & 0.1460 & 0.1574782 & -0.01151 & 0.00013237 & 1 \\
\hline 16 & 0.1068 & 0.1285856 & -0.02182 & 0.00047600 & 0.1031 & 0.1286186 & -0.02556 & 0.00065322 & 1 \\
\hline 17 & 0.1023 & 0.127993 & -0.02573 & 0.00066192 & 0.1033 & 0.1281216 & -0.02484 & 0.00061684 & 1 \\
\hline \multirow[t]{3}{*}{18} & 0.1064 & 0.127891 & -0.02149 & 0.00046183 & 0.1026 & 0.1282922 & -0.02569 & 0.00065982 & 1 \\
\hline & & & Total & 0.01799908 & & & Total & 0.74405096 & \multirow[t]{2}{*}{$94 \%$} \\
\hline & & & MSE & 0.00099995 & & & MSE & 0.04133616 & \\
\hline
\end{tabular}

Keterangan :

$1=$ Benar $\quad 0=$ Salah

Pada tabel 5 dapat dilihat perbandingan dari 6 model arsitektur jaringan yang digunakan. dari ke 6 model arsitektur ini, tingkat poch dan waktu diperoleh dengan menggunakan aplikasi Matlab. Sedangkan MSE dan Akurasi dari masingmasing model arsitektur diperoleh dengan menggunakan perhitungan pada Microsoft Excel. Model arsitektur terbaik adalah 4-8-1 yang menghasilkan tingkat akurasi sebesar $94 \%$.

Tabel 5. Perbandingan Akurasi Model Arsitektur Backpropagation

\begin{tabular}{|c|c|c|c|c|c|}
\hline \multicolumn{5}{|c|}{ Backpropagation } \\
\hline \multirow{2}{*}{ No } & \multirow{2}{*}{ Arsitektur } & \multicolumn{2}{|c|}{ Training } & \multicolumn{2}{c|}{ Testing } \\
\cline { 3 - 6 } & & Epoch & MSE & MSE & Akurasi \\
\hline 1 & $4-2-1$ & 10000 & 0.00180165 & 0.10946508 & $83 \%$ \\
\hline 2 & $4-3-1$ & 1615 & 0.00099987 & 0.02609104 & $78 \%$ \\
\hline 3 & $4-4-1$ & 7894 & 0.00099936 & 0.03511963 & $83 \%$ \\
\hline 4 & $4-5-1$ & 545 & 0.00099933 & 0.01972915 & $78 \%$ \\
\hline 5 & $4-8-1$ & 1419 & 0.00099995 & 0.04133616 & $94 \%$ \\
\hline 6 & $4-10-1$ & 304 & 0.00099902 & 0.00901570 & $72 \%$ \\
\hline
\end{tabular}

Setelah mendapatkan arsitektur terbaik, selanjutnya dengan menggunakan model 4-8-1 dan parameter yang sama maka, akan dilakukan prediksi 5 tahun kedepan dengan menggunakan backpropagation. Hasil prediksi 5 tahun kedepan dapat dilihat pada tabel 6 . 
Tabel 6. Hasil Prediksi 5 Tahun Kedepan Dengan Backpropagation (2018-2022)

\begin{tabular}{|c|l|c|c|c|c|c|}
\hline No & \multicolumn{1}{|c|}{ Data } & $\begin{array}{c}\mathbf{2 0 1 8} \\
\text { Liter }\end{array}$ & $\begin{array}{c}\mathbf{2 0 1 9} \\
\text { Liter }\end{array}$ & $\begin{array}{c}\mathbf{2 0 2 0} \\
\text { Liter }\end{array}$ & $\begin{array}{c}\mathbf{2 0 2 1} \\
\text { Liter }\end{array}$ & $\begin{array}{c}\mathbf{2 0 2 2} \\
\text { Liter }\end{array}$ \\
\hline 1 & Advance AX3 & 38462 & 38049 & 74354 & 84309 & 111957 \\
\hline 2 & Advance AX5 & 88047 & 67681 & 84468 & 191920 & 192571 \\
\hline 3 & Advance AX7 & 90300 & 81901 & 98655 & 200792 & 209678 \\
\hline 4 & Advance AX7 Matic & 6331 & 5550 & 6310 & 6008 & 6185 \\
\hline 5 & Advance Sx2 & 7961 & 5633 & 6753 & 5988 & 6303 \\
\hline 6 & Advance Ultra 4T & 5106 & 5515 & 6081 & 5986 & 6117 \\
\hline 7 & Helix HX3 & 93140 & 74114 & 74685 & 200236 & 190342 \\
\hline 8 & Helix HX5 & 175935 & 210362 & 199887 & 214025 & 210760 \\
\hline 9 & Helix HX7 & 97675 & 110853 & 109143 & 197272 & 215315 \\
\hline 10 & Helix HX8 & 5796 & 5706 & 6148 & 6035 & 6140 \\
\hline 11 & Helix Ultra & 5124 & 5515 & 6083 & 5990 & 6119 \\
\hline 12 & Rimula R2 40 & 18234 & 8482 & 16327 & 8351 & 10975 \\
\hline 13 & Rimula R2 Extra & 5611 & 5882 & 6063 & 6071 & 6116 \\
\hline 14 & Rimula R3 X & 5076 & 5519 & 6075 & 5986 & 6116 \\
\hline 15 & Rimula R4 X & 16070 & 9066 & 11665 & 7219 & 8202 \\
\hline 16 & Spirax S2G & 5144 & 5511 & 6084 & 5990 & 6120 \\
\hline 17 & Spirax S3 ATF & 5122 & 5558 & 6070 & 5996 & 6115 \\
\hline 18 & Spirax S3 G & 5200 & 5520 & 6094 & 5989 & 6122 \\
\hline
\end{tabular}

\section{KESIMPULAN}

Kesimpulan yang dapat diambil dari penelitian ini antara lain :

a. Dengan model arsitektur 4-8-1, dapat melakukan prediksi jumlah penjualan oli shell dengan tingkat akurasi $94 \%$.

b. Model Arsitektur jaringan serta parameter yang digunakan sangat mempengaruhi tingkat training dan testing.

c. Hasil dari penelitian ini, diharapkan dapat menjadi bahan pertimbangan bagi PT.Mitra Petra Sejahtera dalam melakukan prediksi penjualan di masa yang akan datang.

\section{DAFTAR PUSTAKA}

[1] M. A. Ridla, "Particle Swarm Optimization Sebagai Penentu Nilai Bobot Pada Artificial Neural Network Berbasis Backpropagation Untuk Prediksi Tingkat Penjualan Minyak Pelumas Pertamina," J. Ilm. Inform., vol. 3, no. 1, pp. 183-192, 2018.

[2] A. P. Windarto, "Implementasi JST Dalam Menentukan Kelayakan Nasabah Pinjaman KUR Pada Bank Mandiri Mikro Serbelawan Dengan Metode Backpropogation," J. Sains Komput. Inform., vol. 1, no. 1, pp. 12-23, 2017.

[3] M. Yanto, S. Defit, and G. W. Nurcahyo, "Memprediksi Jumlah Reservasi Kamar Hotel Dengan Metode Backpropagation ( Studi Kasus Hotel Grand Zuri Padang )," J. KomTekInfo Fak. Ilmu Komput., vol. 2, no. 1, pp. 34-39, 2015.

[4] Agus perdana windarto Anjar wanto, "Analisis Prediksi Indeks Harga Konsumen Berdasarkan Kelompok Kesehatan Dengan Menggunakan Metode Backpropagation," Sinkron, vol. 2, no. 2, pp. 37-44, 2017.

[5] A. Wanto, "Penerapan Jaringan Saraf Tiruan Dalam Memprediksi Jumlah Kemiskinan Pada Kabupaten/Kota Di Provinsi Riau," Kumpul. J. Ilmu Komput., vol. 05, no. 01, pp. 61-74, 2018.

[6] A. T. Solikhun, M. Safii, "Jaringan Saraf Tiruan Untuk Memprediksi Tingkat Pemahaman Siswa Terhadap Matapelajaran Dengan Menggunakan Algoritma Backpropagation," J. Sains Komput. Inform., vol. 1, no. 1, pp. 24-36, 2017.

[7] Y. A. Lesnussa, S. Latuconsina, and E. R. Persulessy, "Aplikasi Jaringan Saraf Tiruan Backpropagation untuk Memprediksi Prestasi Siswa SMA ( Studi kasus : Prediksi Prestasi Metode backpropagation dalam memprediksi jumlah penjualan oli shell (Chairul Fadlan) | 403 
Siswa SMAN 4 Ambon )," J. Mat. Integr., vol. 11, no. 2, pp. 149-160, 2015.

[8] M. Adi, P. Hutabarat, M. Julham, A. Wanto, P. Algoritma, and M. Produksi, "Penerapan Algoritma Backpropagation Dalam Memprediksi Produksi Tanaman Padi Sawah Menurut Kabupaten/Kota Di Sumatera Utara," semanTIK, vol. 4, no. 1, pp. 77-86, 2018.

[9] Jong Jek Siang, Jaringan Syaraf Tiruan \& Pemrogramannya Menggunakan Matlab. Yogyakarta: Andi, 2009.

[10] E. Hartato, D. Sitorus, and A. Wanto, "Analisis jaringan saraf tiruan untuk prediksi luas panen biofarmaka di indonesia," semanTIK, vol. 4, no. 1, pp. 49-56, 2018.

[11] Swastha, Basu. 2015. Manejemen Pejualan, Edisi III. Yogyakarta: Bpfe 